\title{
The Impact of Financial Regulation on the Development of Distributed Ledger Technology (DLT) Firms
}

\author{
Loha Hashimy ${ }^{1 *}$ and Philipp Sandner ${ }^{2}$ \\ ${ }^{1}$ Department of Business, Facultat d'Economia i Empresa, Universitat Autònoma de Barcelona, Barcelona, Spain, ${ }^{2}$ Frankfurt \\ School Blockchain Center, Frankfurt School of Finance and Management, Frankfurt, Germany
}

There is disagreement in the literature concerning the impact of regulations on firms' development. While some researchers believe that regulation impedes companies' development (Jalilian et al., 2007; Poel et al., 2014), others argue that regulations enable companies' development (Mayson et al., 2014; Peck et al., 2018). This paper aims to contribute to a better understanding of the impact of financial regulations on development of token-based Distributed Ledger Technology (DLT) firms. In-depth semi-

OPEN ACCESS

Edited by:

Horst Treiblmaier,

MODUL University Vienna, Austria

Reviewed by:

Jason Potts,

RMIT University, Australia

Henry Michael Kim,

York University, Canada

*Correspondence:

Loha Hashimy

loha.hashimy@fs-blockchain.de; loha.hashimy@gmail.com

Specialty section:

This article was submitted to

Financial Blockchain,

a section of the journal

Frontiers in Blockchain

Received: 21 August 2019

Accepted: 17 April 2020

Published: 27 May 2020

Citation:

Hashimy L and Sandner P (2020)

The Impact of Financial Regulation on

the Development of Distributed

Ledger Technology (DLT) Firms.

Front. Blockchain 3:21.

doi: 10.3389/fb/oc.2020.00021 structured open-ended interviews have been conducted with 20 DLT firms in Europe during April and May 2019. Our results show that the impact of financial regulation can be ambiguous as it can both enable and constrain a firm's development.

Keywords: DLT, financial regulation, firms, blockchain, innovation, digital transformation

\section{INTRODUCTION}

Regulatory frameworks are sometimes considered as positive impulses for the uptake of a technology (Mayson et al., 2014; Peck et al., 2018) and sometimes as excessive compliance burdens (Jalilian et al., 2007; Poel et al., 2014). When it comes to Distributed Ledger Technologies (DLT), a shared, replicated, and synchronized database that is stored in multiple places at the same time, regulatory responses at the international level have been quite diverse. In Europe, although some countries such as Liechtenstein, Switzerland, Malta, and Franc are among the pioneers in passing bills for the establishment of a regulatory framework for DLT token-based applications, the European Union (EU) has shown interest but has adopted a more conservative approach.

Using a peer-to-peer network or a distributed ledger, cryptography (using codes to protect information and enable a secure way of communication), and smart contracts (auto-executed contracts once a predefined condition is met) lots of processes that depended on the third parties can be disintermediated and automized. In this paper, we refer to a combination of these technologies as DLT. Although DLT got the attention with the cryptocurrency (digital currencies that use cryptography to secure transactions and avoid double-spending) hype of 2017-2018, it introduced a completely new way of transferring assets and anything of value also known as tokenization. Trustworthy Technology (TT), also known as Blockchain, Act of Liechtenstein (2019, P2) defines token "a piece of information on a TT System which: (1) can represent claims or rights of memberships against a person, rights to property or other absolute or relative rights; and (2) is assigned to one or more TT Identifiers." In such a token "container" model, that is used in this paper, a token is 
a digital representation of any right, certificate, obligation or assets (tangible or intangible) such as a car, a digital identity, a piece of art, an idea or an innovation the same as the right to vote, the right to access a program, and the right to rent. For instance, if the token container is filled with a house then the token transaction has to comply with the laws concerning real estate ownership.

A regulatory framework should foster the uptake of innovation and prevent fraudulent actions. As the use of DLT is growing exponentially, it also raises new challenges in the digital markets across the globe. Some DLT applications do not fit into the current regulatory framework as they change existing institutions and disrupt centralized systems. Using DLT, there will be no need for trusted intermediaries for the registry of transactions, verification, accountability, and identity. Due to this fact, the task becomes even more difficult. Governments are facing the challenge of striking a balance between providing a minimal regulatory framework, which gives a boost to the ecosystem and leaves entrepreneurs free to experiment with the most innovative ideas, and on the other hand, ensuring market stability and preventing malpractice opposing unforeseeable risk at involved participants.

While there are different types of regulations (e.g., economic, social, institutional, and environmental), this paper focuses on financial regulations. The reason behind is that some of the most prominent use cases of DLT, including its first application Bitcoin, are related to finance and financial services. Moreover, as token-based applications of DLT are related to transfer of value or rights, the transactions at any moment can be subject to financial regulation. In some European countries, even if the application is not related to finance the company has to go through financial regulation and inspection for obtaining an operational license. The paper aims to scrutinize the perception of small-medium DLT company owners or managers concerning the financial regulations related to DLT. Precisely, we seek to answer the following main research questions: what are the challenges that DLT token-based companies are facing with financial regulations? And what are the expected impacts of these regulations on the development of DLT firms? This way, we aim to fill in the information gap between regulatory institutions and DLT company owners or managers.

Semi-structured open-ended interviews are conducted with a number of DLT related companies during April and May 2019. The results not only contribute to the understanding of how the regulation can slow down or, as the contrary, propitiate the implementation and diffusion of a new technology but also can be used to draw policy recommendations and practical implications for the countries that are in the process of developing legislation and legal framework regarding DLT. To the best of our knowledge, this is the first paper that investigates the expected impact of financial regulations on DLT firms.

The remainder of this paper is structured as follows. We provide a short background on DLT, the EU's initiatives, and some existing DLT financial regulation challenges that DLT companies are facing. In the next section, we will review the literature on the impact of regulations on the firms. Next, the methodology used is explained and a short description of the data is presented. Furthermore, a section has been dedicated to the results. The last section of the paper is dedicated to the conclusion, discussion, and practical implications.

\section{BACKGROUND}

\section{Distributed Ledger Technology (DLT)}

Databases can be centralized, controlled by a single entity and stored in a specific physical or geographical place, or decentralized, controlled by different entities and stored in different physical/geographical places. European Central Bank (2016, p1) defines a distributed ledger as "A record of information, or database that is shared across the network." It can be public (permissionless), meaning that anyone can join the network, make changes, and generate new transactions, or private (permissioned), which means that only specific people can join the network, access the information, and limited people can bring changes to the system. A combination of public and a private DLT is called Hybrid, in which participation might be partially restricted.

There are different ways to record the transactions in a DLT, one of them is Blockchain. In a Blockchain, bundles of transactions are timestamped and stored into blocks and the blocks are connected (chained) in a chronological way with each other by cryptographic hashes. Another way to store and process data in a decentralized way is Directed Acyclic Graphs (DAG). An Acyclic graph is a graph without complete circuits or cycles, which means that if you follow node by node a sequence of edges (the lines going from one node to another), you will never visit the same node twice. Then DAG is an acyclic graph that has direction.

As noted in Figure 1, while some DLT might use tokens (e.g., Bitcoin and Ethereum), some others are token-less (e.g., Hyperledger and Multichain). It should be mentioned that although cryptocurrency tokens can be generated using DLT, not necessarily all tokens are cryptocurrencies. Tokens can be used to

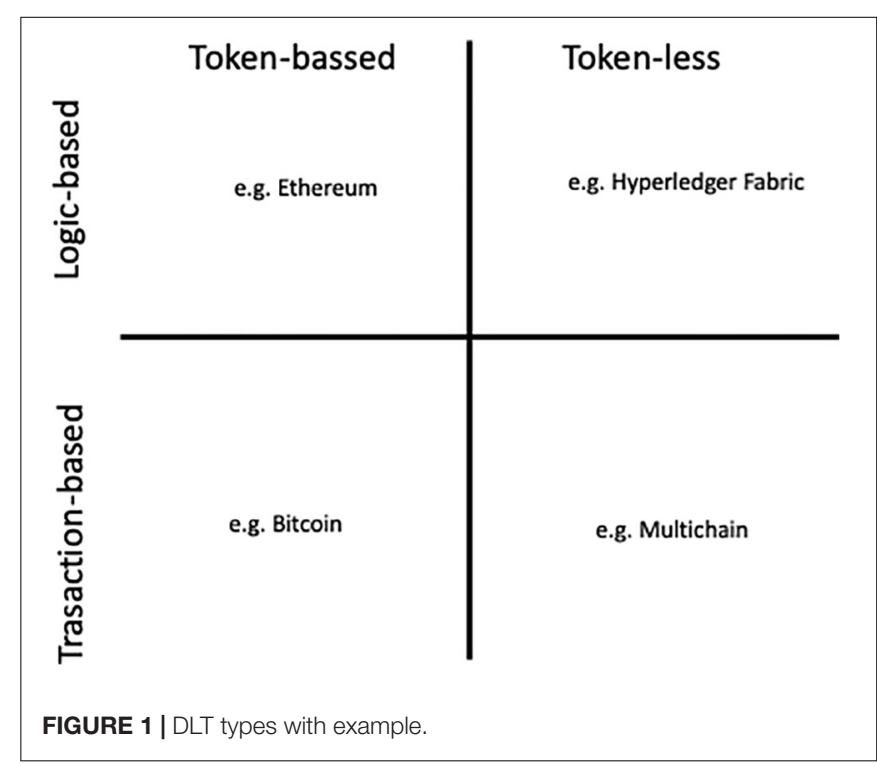


transfer a right, such as ownership, leasing, or lending of a car, a house, a painting, a machine. . .etc. It can also be used as evidence of an event occurrence at a certain time. For example, a token can represent a proof of voting, registration of a certificate, or creation of an idea. Tokens in some permissionless decentralized networks are used to incentivize the members to maintain the system correct and updated. Tokens in such cases can be considered as the network's fuel which help to run the system properly. In some other cases, it is used as equity (a stake or ownership), or as a claim to an asset that is tradable. Permissioned networks as R3 and Corda don't use tokens. In such networks, DLT is used to eliminate the middleman and cut the costs, to increase transparency between the stakeholders, to track the state of a transaction, and to increase privacy and systems' security. Thus, the backbone technology can be used as an instant, temper-proof, shared database for record keeping without a token to improve the existing internal processes of an entity.

Another distinction between DLT applications can be associated to running logics. Some platforms have combined smart contracts with DLT to enable running certain logics or predefined commands (e.g., Ethereum), which we call logic-based DLT. But there are other types of DLT that are aimed only to track transactions (e.g., Bitcoin), which we call transaction-based DLT. Although one might argue that Bitcoin is run through a smart contract, Ethereum allows generating any type of smart contracts that not necessarily have to aim tracking transactions.

To sum up, DLT in its essence is a distributed digital database. It can be combined with other technologies as smart contracts or cryptography to enable a decentralized way of storing data and transferring value. DLT can be classified in different ways based on type of the network structure or governance (permissioned, permissionless or hybrid), type of data storing (Blockchain or DAGs), token-based and token-agnostic DLT, and logic-oriented or transaction-oriented DLT.

\section{EU Initiatives}

The EU has already launched various initiatives to assess the regulatory needs of DLT. Shortly after the introduction of the first application of the technology (Bitcoin cryptocurrency) in 2012, European Central Bank (ECB) released a report about the implications of virtual currencies for the monetary policy. ${ }^{1}$ But up until 2015, not a lot of importance was given to it. Once the acceptance and market capitalization of virtual currencies started growing, ECB started analyzing cryptocurrencies' potential threats to the monetary policy. A timeline of the EU's initiatives related to DLT's development can be seen in Figure 2 . It should be highlighted that the EU's focus so far has mainly been attached to the financial regulation of cryptocurrencies and its potential impact on the monetary policy. Defining a legal framework for other applications of the technology and its potential to decentralize many markets across many fields have been kept on the margin.

\footnotetext{
${ }^{1}$ European Central Bank (2016) Virtual currency schemes - a further analysis, Eurosystem Report www.ecb.europa.eu/pub/pdf/other/ virtualcurrencyschemes201210en.pdf.
}

The European Digital Single Market Strategy (DSMS) ${ }^{2}$ was created in 2015 to ensure individual and businesses access to online activities. In the same year, European Court of Justice (ECJ) announced that any transaction (buying or selling) and exchange of fiat currencies for the Bitcoin cryptocurrency and vice versa is exempted from Value Added Tax (VAT) ${ }^{3}$. A legislative proposal from the European Commission was presented to European Parliament Directive and Council Amending Directive, in July 2016, obligating all custody wallet providers to go through due diligence process to prevent, detect, and report Anti-Money Laundering (AML) and terrorism financing. ${ }^{4}$ In 2018 , the proposal was approved and published by the European Union. ${ }^{5}$

Blockchain's high potential for public administrations, businesses and society was highlighted in the DSMS mid-term review in May 2017. A few months later, blockchain technology was mentioned as one of the 'key emerging trends' in the council conclusions. ${ }^{6}$ But early 2018, European Supervisory Authorities for Securities (ESMA), European Banking Authority (EBA), and European Insurance and Occupational Pensions Authority (EIOPA) warned consumers about the high risks associated with cryptocurrencies. ${ }^{7}$ The warning also mentioned that virtual currencies are "unregulated under EU law." (ESMA, EBA and EIOPA warn consumers on the risks of Virtual Currencies, 2018, p1.) $)^{8}$

At the same month, the EU Blockchain Observatory and Forum was established to identify, map, and monitor initiatives related to Blockchain technology. ${ }^{9}$ Three thematic reports were published by this initiative since its establishment: the "Blockchain Innovation in Europe" (July 2018), the "Blockchain and the General Data Protection Regulation" (October 2018) and "Blockchain for Government and Public Services" (December 2018).

Almost one month later, the European Commission released an action plan on the opportunities that new technologies such as Blockchain, and artificial intelligence can bring to FinTech

${ }^{2}$ European Single Digital Market Strategy, European Commission, https://ec. europa.eu/commission/priorities/digital-single-market_en.

${ }^{3}$ Case C-264/14, Skatteverket v. David Hedqvist, archived at http://perma.cc/ 7Q6Q-MM9V.

${ }^{4}$ Proposal for a Directive of the European Parliament and of the Council Amending Directive (EU) 2015/849 on the Prevention of the Use of the Financial System for the Purposes of Money Laundering or Terrorist Financing and Amending Directive 2009/101/EC, COM (2016) 450 final (July 5, 2016), https://eur-lex.europa.eu/legalcontent/EN/TXT/PDF/?uri=CELEX: 52016PC0450\&from $\sim(==\mathrm{EN}$.

${ }^{5}$ European Parliament, 5th Anti Money Laundering Directive (2018), http://www.europarl.europa.eu/news/en/press-room/20180411IPR01527/antimoney-laundering-meps-vote-to-shed-light-on-the-true-owners-of-companies. ${ }^{6}$ European Parliament, 5th Anti Money Laundering Directive (2018), http://www.europarl.europa.eu/news/en/press-room/20180411IPR01527/antimoney-laundering-meps-vote-to-shed-light-on-the-true-owners-of-companies. ${ }^{7}$ Euroepan Commission, European System of financial revision (2010), https: //ec.europa.eu/info/business-economy-euro/banking-and-finance/financialsupervision-and-risk-management/european-system-financial-supervision_en.

${ }^{8}$ European Banking Authority, ESAs warn consumers of risks in buying virtual currencies (2018), https://eba.europa.eu/-/esas-warn-consumers- of-risksin-buying-virtual-currencies.

${ }^{9}$ European Commission, EU Blockchain Observatory and Forum (2018), https:// ec.europa.eu/digital-single-market/en/eu-blockchain-observatory-and-forum. 


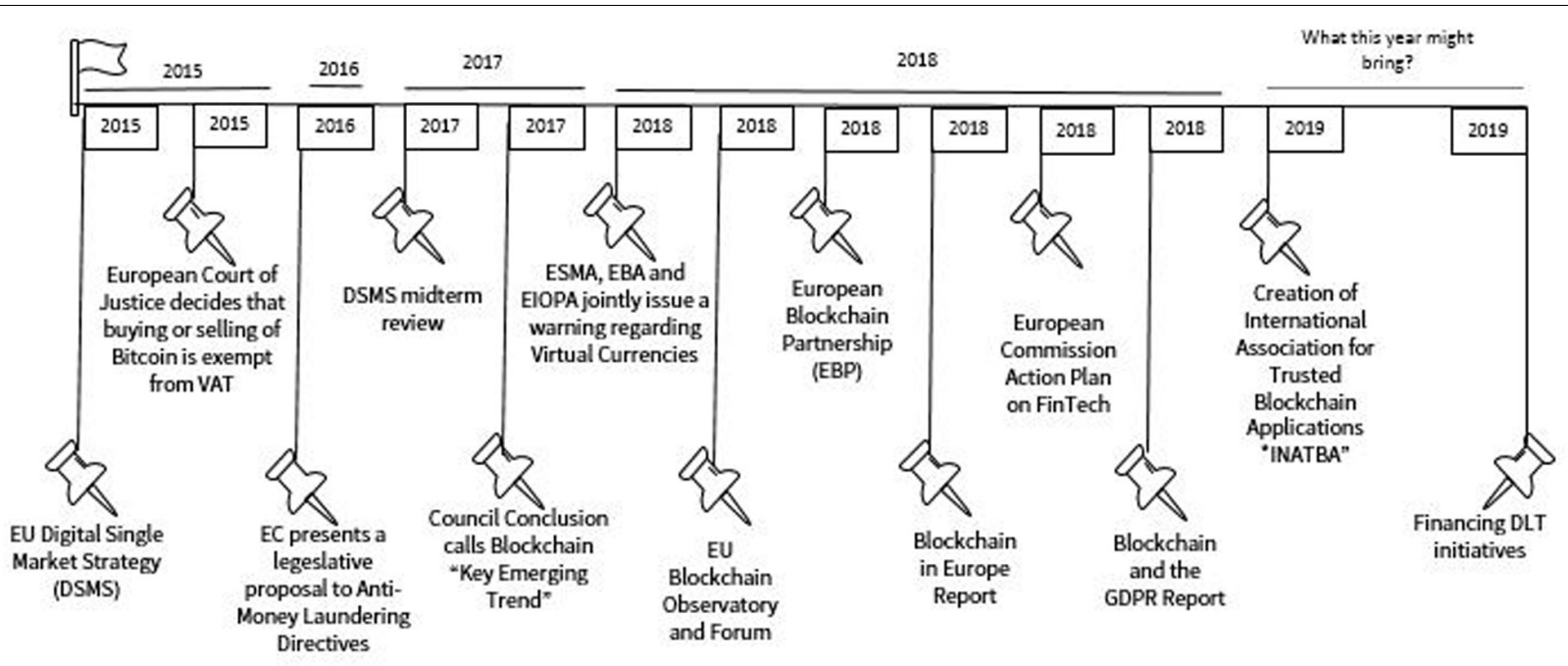

FIGURE 2 | Timeline of EU initiatives related to DLT development.

and other economic sectors. ${ }^{10}$ It was followed by the European Blockchain Partnership (EBP) and Blockchain in Europe Report. EBP was launched to develop a trusted, secure and resilient European Blockchain Service Infrastructure (EBSI). It was signed by 26 member states and Norway. ${ }^{11}$ The International Association for Trusted Blockchain Applications (INATBA) was founded in March 2019 to establish a dialogue with global policy makers to foster a convergence of the legal frameworks applying to the distributed network economy. ${ }^{12}$

Since 2016, the EU has invested over EUR 141 million in projects supporting the use of Blockchain in technical and societal areas and around EUR 340 million are to be allocated by $2020 .^{13}$ Although significant effort has been put to make the EU an attractive and safe place for DLT companies, but DLT companies are still faced with legal uncertainty and lack of legal guidelines.

\section{Financial Regulation Challenges That DLT Firms Face}

Decentralization, where the need for a central agency is eliminated, is the disturbance that DLT can bring to the current centralized political, social, and economic systems. The development and introduction of digital currencies and the effect they have had on the economic and banking sectors would be an instance of this. Bitcoin's success in disintermediating the monetary system by eliminating the role of central banks and resolving the double-spending problem has already raised concerns about the government's control over monetary policy.

\footnotetext{
${ }^{10}$ European Commission Action plan on Fintech (February 2018), http://europa. eu/rapid/press-release_IP-18-1403_en.htm.

${ }^{11}$ European commission, European countries join Blockchain Partnership (2018), https://ec.europa.eu/digital-single-market/en/news/european-countriesjoin-blockchain-partnership.

${ }^{12}$ European commission, Digital Single Market, Blockchain Technology (2019), https://ec.europa.eu/digital-single-market/en/blockchain-technologies.

${ }^{13}$ European Commission, Blockchain technologies (May 2019), https://ec.europa. eu/digital-single-market/en/blockchain-technologies.
}

In contrast to the belief that DLT allows only money and payments to be decentralized, it can alter the market structure across different sectors. The next generation of DLT has the potential to dramatically automate or digitize both tangible and intangible assets, rights, and obligations.

In today's world, it is the responsibility of economic officials to regulate anything associated to value transfer and exchange. Thus, DLT's first applications that are primarily attached to asset tokenization such as money, stocks, bonds, and equity have attracted the EU's financial regulator's attention. But after more than 10 years of cryptocurrencies existence, it seems governments are still struggling to pin down fundamental issues such as provision of a precise definition of virtual currencies and tokens in general. It is not just the definition and classification of tokens that varies across the EU, taxation of the tokens seems to be blurry and unclear as well.

The main challenge that token-based DLT firms are faced with is lack of a unified EU token definition and classification. For instance, in Germany, while Initial Coin Offerings (ICOs) and Security Token Offers (STOs) are classified as financial instruments, utility tokens do not fall under this classification and thus are not subject to financial prospectus. The Swiss government acknowledged four categories of tokens: payment token, utility token, hybrid token, and asset token. Unlike Germany and Switzerland, where jurisdiction divides tokens into distinct categories, Liechtenstein sets out a detailed fundamental definition of a token that captures all token types. Thus, broadening its far-reaching scope.

It can be noticed that there is no unified definition and classification of tokens. While some countries are in the process of experimentation and have legalized specific type of tokens, some others are already working on defining a legal framework for generic use of tokens such that it encompasses any right.

Since the definition and classification of a token is unified, it generates uncertainty concerning the taxation as well. Although the ECJ announced that Bitcoin transactions fall under VAT 
exemption, a unified tax treatment of tokens in the EU does not exist. For instance; the Danish Tax Council indicated in 2018 that losses on the sale of bought bitcoins as an investment are tax deductible and that earnings are taxable. While in France, depending on the type of token issued, corporate revenue tax applies differently. Personal income tax is applied at a flat rate of $30 \%$ for the tokens qualifying as financial instruments.

The other challenge that DLT token related companies are faced with, is - albeit trivial - opening a bank account. For instance, by law, Estonian banks are not allowed to open bank accounts for token generating companies. However, in Germany, some banks allow token exchanges, such as Fidor Bank and VPE Bank. In general, in most other European countries as the Netherlands, Spain and Switzerland companies are struggling to open a bank account due to inability to comply with KYC and AML. It is believed that the banks in Europe are reluctant in opening a bank account for token issuing companies due to a not fully regulated market.

It can be concluded that DLT businesses face important difficulties owing to the ambiguity of legislation or absence of a unified DLT legislation in the EU, such as coping with a clear classification of tokens, tax treatment of tokens, and establishing a bank account.

\section{The Impact of Financial Regulation on DLT Firms}

Searching the word "blockchain" would have given more than 20.000 results in 2014 and the number has increased to about 80.500 by 2019 . It is not only the number of publications that have increased more than fourfold during the last 5 years. Debates and discussions on the challenges to the adoption of the technology have grown exponentially as well. While companies are intending to embrace technology, regulatory uncertainty remains one of the main barriers (Carson et al., 2018). Government's stance is varying worldwide. While some countries have been totally against the token economy and blockchain, some others have tried to be engaged and create a favorable environment for DLT companies. The EU has been quite conservative and strict regarding the ICOs and STOs. Although some countries such as Malta, Switzerland, France, and Liechtenstein have chosen a more progressive approach and are among the pioneers in passing bills for the establishment of a regulatory framework for DLT.

According to the World Bank (2014), regulation is a tool to protect citizens, environment and foster economic growth. The impact of regulation on business and economy has been reviewed extensively in the literature over the past years and has been the focus of discussion between policymakers, academic researchers and practitioners in economics and politics. Although in recent years many papers related to DLT/Blockchain have been published, we have found few discussion papers highlighting the importance of regulation and some articles on the general legislative issues concerning Blockchain. Decentralization, transparency, anonymity, and democracy are some of the features that DLT systems can provide. As the original idea of DLT is coming from anti-system cypherpunks, who were against trusted third parties, there are supporters and opponents of DLT regulation.

Supporters of DLT regulation claim that inconsistency of policies and regulatory uncertainty can have negative implications on the adoption and diffusion of DLT. It is believed that a lack of a clear articulation of government position can limit the applications, hinder development, and reduce the attractiveness of DLT (Tapscott and Tapscott, 2016; Lacity, 2018). As the first application of DLT, Bitcoin and cryptocurrencies in general, seems to have raised some debate in the literature. But, the arguments can be applied to other decentralized applications that are token-based as well. Chohan (2018), in a discussion paper on the agents' responses to BitLicense (virtual currency business licenses issued by the New York State Department of Finance), argues that although at least 10 token and DLT related companies stopped their business in New York since BitLicense has come to affect, "regulatory responses are not just desirable, but necessary as the volatile and decentralized nature of cryptocurrencies raises simmering questions about their relationship to organized and regulated markets and societies." (Chohan, 2018, p. 4). Tsukerman (2016) classifies regulations around Bitcoin into the ones that protect the users (consumers and investors) and the ones that protect society from malicious usage of Bitcoin such as money laundering, terrorism, drug dealing, and criminal activities. He suggests that the government should accept Bitcoin as a currency and medium of exchange, but should "deanonymize" it by requiring the network participants to reveal their identities.

On the other hand, opponents of DLT regulations argue that the technology is still at its early stages and governmental intervention can be detrimental to its progress. A research was done by Yeoh (2017) on the regulatory issues of Blockchain suggests "minimum regulatory brakes" in order not to discourage the innovative spirits that contribute to the transformation of existing systems.

Although the above-mentioned papers highlight the importance of DLT regulations, none of them has studied the potential impact of regulations mainly financial regulations on DLT related companies, thus limiting their applicability to our study. To our knowledge, this is the first paper that investigates the regulatory hurdles that DLT token-based companies that have to go through and its expected impact on the firm's development.

\section{METHODOLOGY AND DATA}

Taking into consideration the need for more in-depth qualitative, and explorative firm-level studies on the impact of regulations on businesses (Capelleras et al., 2008; Kitching et al., 2015; Peck et al., 2018). This paper uses semi-structured, open-ended interviews with owners or managers of 20 DLT companies from different European countries to draw insights on the impact of financial regulations on the perception of owners or managers of the firms and the development of the firm. 
The desktop search was conducted to create a list of DLT companies based in the EU. Emails and LinkedIn messages were sent to targeted people. A total of 10 CEOs and managers agreed to take part in the study. The sample was then extended to 20 until data saturation was reached (Guest et al., 2006). The sample is constructed of four types of DLT-related companies; DLT consulting firms, DLT token issuers, exchange services platforms, and custody service providers. DLT consulting firms are companies that provide legal, technological, or financial consultancy services. Token exchange service platforms are the companies that provide exchange services, either crypto-crypto, crypto-fiat or fiat-crypto. Token issuers are the companies that use DLT technology to issue tokens as digital-currencies, utility tokens, security tokens, or any other right that can be packed in a token. Custody service providers are third party entities that safeguard, maintain and protect other company's assets or DLT consumers' private keys or identity. Five out of 20 companies are DLT consulting firms. These five interviews have been used to get insight on the registration process, legal and financial challenges that DLT companies are faced with and more importantly, to acquire background knowledge on the topic. Moreover, the experts' opinion gave us some hints in constructing the semi-structured open-ended interviews in a way to capture as much information as possible and defining when data saturation can be reached. Three out of five interviewees are legal experts and have been engaged in consulting different EU countries in drafting DLT related financial regulations. Thus, their opinion is considered to be biased and has been used only as background information for the researchers. The sample size meets the threshold proposed by Creswell (2006) to establish a reliable consensus in heterogeneous samples. Although the sample is homogeneous in company size and all the companies are related to DLT, it is heterogeneous in sector and location. The interviews were done during April and May 2019.

The structure of the interviews follows some qualitative studies that are reviewed in the literature. Mainly, Achtenhagen et al. (2017) paper is taken as a reference. As it can be seen in Figure 3, the flow of the interview goes from the registration to companies' owners' recommendation to EU. First, the entrepreneurs were asked to give a short introduction to the company and narrate the development of the firm since inception. Then, they were asked about the registration process, if they had to go through licensing, complying with any specific regulation, going through any audit, etc. and if the company faced any challenges during the process. Further, they were asked if financial regulation influences their businesses and affects the company's growth ambitions. Next, the perception of the interviewee was investigated regarding the current regulations. In the end, they have been asked for suggestions and recommendations to the EU.

The interviews lasted between 30-45 min. All the interviews were recorded and transcribed. Then the transcripts were analyzed for writing a two to three-page vignette (Achtenhagen et al., 2017). Furthermore, vignettes within each cluster were compared and cross-case analysis was conducted to find similarities and differences. As it can be seen in Table 1, 60\% of the interviewees were token issuing companies or companies that were planning to issue tokens in the future. Twenty five percent of the sample is represented by the DLT consulting companies that provide legal, financial, and technology consulting services. Only $5 \%$ of the sample is the token exchange services platform and another $10 \%$ custody services.

\section{RESULTS}

As the consulting firms go through the normal registration process for any company, they are not faced with any challenges related to financial regulations or getting a license. Only two companies had to go through extra inspection as the word DLT and Blockchain was mentioned in their application form. One of the consulting firms that accept tokens is experiencing some problems in opening a bank account and dealing with taxation.

"One of the difficulties, even until today, is to create a bank account, as we do accept cryptocurrencies. Another problem is finding a tax consultant that is ready to do our tax audit, because; some of them do not really understand token transfers." (Interview, Cofounder, 18).

The main results of the paper are drawn from the interviews done with 15 DLT companies that deal with tokens directly and have to get a financial license in order to operate legally under financial regulations of Europe.

Five out of the 15 firms that we have interviewed had successfully issued tokens in Europe. Seven companies are in the process of issuing a token or are planning to issue it in the future, one company is registered as an exchange service platform and there are two custody service providers in the sample. In the following, we will analyze these companies opinion about financial regulations, the challenges they are faced with, the impact of the challenges on the business development, and their expected solution or suggestions to the EU.

\section{Opinion About Financial Regulation}

Most of the interviewees are positive about the financial regulations or having a clear framework within which to operate legally. Regulations are expected to be good for companies. It is believed that defining a legal framework for the tokens can give legal certainty and clarity on what is allowed and what is not allowed. Also, it is assumed that financial regulations can protect consumers, investors, and society from the scammers and give peace of mind to the users and company owners. Passing through financial regulations and having a license is associated with trustworthiness, higher quality, and credibility. It is also believed that a concise and clear regulation can reduce the risk that is associated with the tokens, and increase the trust in the technology and tokens in the society. According to one of the CEOs, "Getting all the certificates means that you are adding credibility to your business." (Interview, Cofounder 9).

Another CEO mentions that "I think for us, it's very good to have legislation because it's going to give confidence and peace of mind to our users." (Interview, Cofounder 2). Also, it is emphasized that over-regulation should 


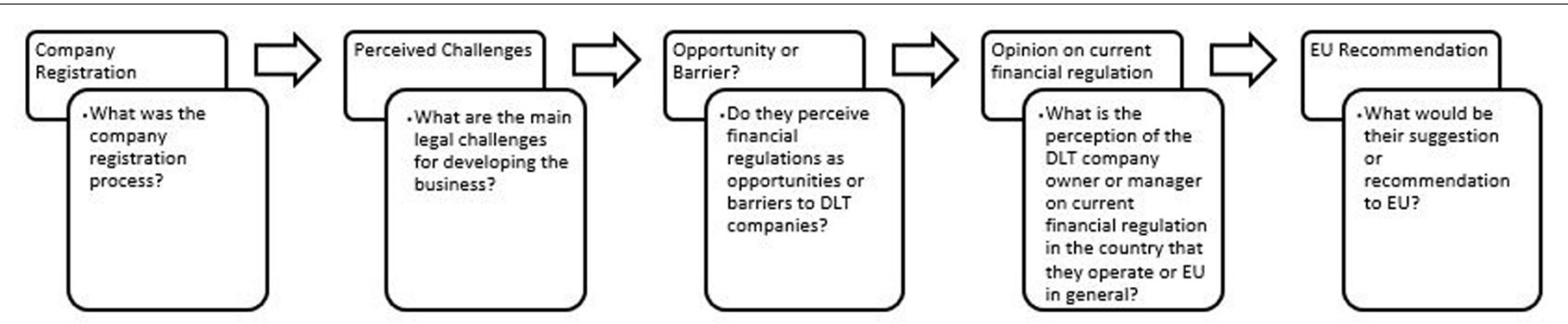

FIGURE 3 | Interview flow.

TABLE 1 | Sample description.

\begin{tabular}{|c|c|c|c|c|c|}
\hline Firm & Sector & Size & Position & Location & Type \\
\hline 1 & Blockchain Analytics tools & 3 & Co-founder and CEO & France & DLT consultancy \\
\hline 2 & Identity verification & 8 & Co-founder and CTO & Malta & Custody Service \\
\hline 3 & Food supply chain management & 4 & Founder & Malta & Token issuer \\
\hline 4 & Real Estate & 9 & Co-founder & Slovenia & Token issuer \\
\hline 5 & Supply Chain Finance & 3 & Business Developer & Germany & Token issuer \\
\hline 6 & $\mathrm{IP}$ & 5 & Co-founder and Business Developer & Germany & Token issuer \\
\hline 7 & Accelerator & 4 & Managing Director & Malta & Token Issuer \\
\hline 8 & Blockchain services & 25 & Marketing Director & Malta, Singapore and Korea & Token issuer \\
\hline 9 & Token Exchange platform & 20 & Founder and CEO & Liechtenstein and Estonia & Token Exchange Services \\
\hline 10 & Financial Services (loan) & 50 & Co-founder & Switzerland, UK, Malta, Estonia & Token issuer \\
\hline 11 & Investment Platform & 5 & Co-founder and CTO & Germany & Token issuer \\
\hline 12 & Banking & 70 & Business Developer & Liechtenstein & Custody Services \\
\hline 13 & Education Certification & & Co-founder and COO & France & Token issuer \\
\hline 14 & Agricultural Supply Chain & 10 & Co-founder & Switzerland and US & Token issuer \\
\hline 15 & Accounting-consultancy & 3 & Co-founder & Malta & DLT consultancy \\
\hline 16 & Computer and Network Security & 7 & Founder and CEO & Germany & Token issuer \\
\hline 17 & Consulting Services & 4 & Co-founder & Germany & DLT consultancy \\
\hline 18 & Consulting Services & 2 & Co-founder & Latvia & DLT consultancy \\
\hline 19 & Education & 4 & Co-founder and CEO & Germany & Token issuer \\
\hline 20 & Consulting Services & 5 & Founder & Malta & DLT consultancy \\
\hline
\end{tabular}

be prevented as excessive regulations are considered to hinder innovation and creativity. One of the company owners says, "What's key is that these regulations should not be saying you must do this or that, because if you are told what to do then innovation is completely stopped. [...] Regulations should not limit the companies so that innovation that might go against regulation is not pushed away and not look down upon and it's still embraced." (Interview, Cofounder 15).

Minimum financial regulation or an update of existing regulations is inquired. It is suggested that policymakers should understand the technology in order to come up with a balanced legal framework that spurs innovation and protect society from malicious actions.

Overall, there is a consensus that having a minimum clear, concise and DLT friendly legal framework for the companies that deal with tokens is important. But, it should be noted that if it is surpassed, it can harm innovation and creativity. Thus, although company owners have a positive attitude toward a minimum legal framework to secure consumers and investors from malicious actions, it is also highlighted that there is no need for more or excessive regulations.

\section{Perceived Challenges}

Most of the companies face some challenges going through financial regulations. When asking about the registration process, a CEO of a DLT company that has passed through issuing a token says, "There are two ways that a serious company can play. One way is to do regulatory arbitrage, meaning that the company, for certain operations, choose some jurisdictions where regulation is lighter or non-existent and then for other parts of their business, apply for licenses. The other way is to apply for licenses everywhere that the company wants to operate in." (Interview, Cofounder 11).

It seems that while in some countries it is easier to get certificates, in others the process is complicated. As of December 2017, all virtual currency exchanges and custodian wallet providers in the EU have to go through the AML check. The companies that have not issued token yet, some have gone through the regular financial company registration process, but some others are still in the process of getting a certificate 
from the authorities. Some of the expected challenges by the company owners and managers and their potential impact on firm development can be seen in Table 2 .

Two challenges that are mentioned by almost all the interviewees are lack of a unified EU financial regulation and regulation clarity. As mentioned by one of the interviewees above, since there is a lack of unified financial regulation concerning tokens in the EU, the company has to acquire a certificate in each country that they operate. Moreover, even when the company wants to apply for a license, as there is no clear definition and classification of tokens, they face confusion on what kind of certificate they have to apply to, what kind of regulations they have to comply with, and tax treatment. That is why, before applying for a license, they almost always have to consult a legal firm, which in most cases is expensive.

Also, the process is considered to be time consuming and slow, since authorities have to go through each case separately. One of the company owners mentions, "If the company wants to expand, it needs to acquire licenses in different countries and this cost money and take time. Thus, they prevent anything to happen quickly." (Interview, Cofounder 6) Another CEO says, "Still the government does not have a good definition for tokens and there is not a proper process defined for the companies to go through." (Interview, Cofounder 5).

Five co-founders that we have interviewed have mentioned lack of guidelines as one of the main challenges that they are faced with. But again, it goes back to the two challenges mentioned above. As far as the countries do not provide a clear definition and classification of tokens and clear financial regulations they will not be able to provide clear guidelines. It is believed that existing financial regulations are old and not updated. Thus, the new technologies or the startups working with technologies as Blockchain do not fit into existing laws. It is believed that there is no need for new regulations, the governments need to just update the old jurisdictions. Another hassle is believed to be going through authorities that have limited knowledge and understanding of DLT. One of the interviewees says: "Most of the challenges that startups are facing are due to lack of Blockchain

TABLE 2 | Expected financial regulation challenges and their impact on DLT companies.

\begin{tabular}{ll}
\hline Expected challenges & $\begin{array}{c}\text { Expected impact on the } \\
\text { company }\end{array}$ \\
$\begin{array}{ll}\text { - Lack a unified financial regulation in } & \begin{array}{c}\text { - It slows down the company's } \\
\text { growth }\end{array} \\
\text { the EU } & \begin{array}{l}\text { - Prevents company's expansion } \\
\text { - Regulation clarity }\end{array} \\
\text { - No guidelines } & \text { - Putting some plans on hold } \\
\text { - Difficulties in opening a bank } & \text { - Limits innovation } \\
\text { account } & \text { - Changing market strategy } \\
\text { - Authorities lack DLT knowledge } & \\
\text { - Slow (time-consuming) certification } \\
\text { procedure }\end{array}$ \\
- Unified tax regime \\
- High costs associated to getting a \\
license
\end{tabular}

understanding from the government side. The government should study it in order to come up with a sustainable way to promote technology in the long term." (Interview, Manager 8).

Another hurdle that companies dealing with tokens come across is opening a bank account. Eighty percent of the interviewees mentioned that opening a bank account is the main challenge that their company has to go through. Not all companies can comply with KYC and AML requirements. Even if they comply with these laws, just knowing that the company works with tokens results in bank account rejections. Explains a co-founder and CEO of a token issuing company, "It's extremely difficult to own cryptocurrencies (tokens) as a company and open a bank account." (Interview, Cofounder 7). Another one mentions, "Right now, startups and companies have the hardest time establishing banking relationships." (Interview, Cofounder $1)$.

To sum up, the main challenges that DLT firms are faced with while going through financial regulations, are either with the existing financial regulations as time-consuming and costly certification process or opening a bank account or due to lack of a clear and unified definition and classification of tokens.

\section{The Impact of Regulation on Firms' Development}

As regards the impact of financial regulation on firms' development, although companies face challenges while complying with the existing regulations, the problem that DLT companies are facing is rather a lack of clear financial regulations. Certainty and clarity of financial regulations is an association of stability, expansion, better planning, and future growth. While at the same time, it is also believed that existing financial regulations are time-consuming and costly and eventually hinders a firm's development. Thus, it is believed that financial regulations can both impede and enable firms' development.

There are two types of financial regulation impact on the development of DLT firms. The first one is associated with the negative impacts of the existing regulations, and the second one is concerned with the negative impacts of unclear or uncertain regulations.

(1) Countries such as Malta and Liechtenstein have enacted financial regulations regarding DLT companies. Custody wallet providers and token issuers in Malta have to go through Digital Innovation Authority (MDIA) Act, Virtual Financial Asset (VFA) Act, and Innovative Technology Arrangements and Services (ITAS) Act. Two companies in the sample have gone through these regulations and two other companies are in the process. One company manager mentions that they had moved to Malta with the hope of having better regulations but have been disappointed as the authorities are still in the process of drafting amendments and have asked for more time to review their case. "As we had to do ICO fundraising, we could not wait 6 more months for the government to approve the license and decided to move to another country with an easier certification process." (Interview, manager 8). 
The impact of complying with such regulations is considered to be negative in some cases. One of the CEOs mentions, that "Although complying with financial regulation is not a problem, it is a matter of efficiency. The less you have to comply with the quicker you can operate and adapt to changing circumstances. It is just timeconsuming and some costs should be taken into account." (Interview, Cofounder 11).

Such delays and costs are assumed to impede a company's growth. "As the procedures are so slow, it slows down the company's growth." (Interview, Cofounder 1). On the other hand, some other company owners believe that going through the process is proving that the company is providing higher quality service and is trustworthy. Getting a certificate can add competencies to the company and can be used as a differentiator. "VFA agents are gatekeepers that primary due diligence and act as a middleman between the DLT companies and the government. Although costly, it helps distinguish the good and bad companies." (Interview, Cofounder 2).

Another interviewee mentions, "As already said, the cost is high and maintaining those costs for a start-up is a great hindrance but on the other hand it enables to filter the companies." (Interview, Cofounder 15).

Thus, passing through the regulations and acquiring a certificate is claimed to have both positive and negative impacts on the firms. A certificate can be used as a tool to add credibility and trust to the business, which can enable growth. It also needs financial resources and thus can impede growth.

(2) Lack of a clear definition, classification, and recognition of tokens on the national level and across Europe are declared to generate some negative impacts on DLT companies' development. Difficulties in structuring a business are one of the negative impacts that are mentioned by two interviewees. One of the company owners argues, "Since there is no unified financial legislation across Europe, it's hard sometimes to structure a business" (Interview, Cofounder 12). Lack of financial regulation clarity has caused some companies to postpone issuing tokens or has pushed them to change their go to market strategy, which again is expected to slow down the company's growth. "It is not clear what is allowed and was banned, we are unable to grow at the rate that we were hoping. We cannot expand at the same rate that we had planned to." (Interview, Cofounder 4) Another co-founder and CEO narrates, "At the beginning, we wanted to issue a token, but knowing that there are no clear token regulations and we have to pass through the financial regulations, which is difficult, we have decided to register a non-profit company for now and start with the simple things that don't need lots of regulations. [...] We have changed our go-to-market strategy." (Interview, Cofounder 5).

Also, it is believed that due to lack of a homogenized EU financial regulation, companies cannot expand the scope of their operation easily as they have to apply for licenses in each country that they want to operate in. one of the CEOs says, "We can't expand and fundraise in an effective way or the way that we had initially planned." (Interview, Cofounder 3).

Again, although it seems that the process is clear in some countries, not having a unified regulation in the EU makes the companies register in various countries in order to be able to operate in all, which in turn means higher costs for the firm and more capital expended in regulatory compliance.

Putting it in other words, it is believed that having minimum, clear, concise, and simple and regulations can create a supportive legal framework that can help companies to execute their plans, expand their market, and grow faster.

To sum up, our findings support Kitching et al. (2015) theory of the dynamic influence of regulations on the firm's development. Regulations can give companies the opportunity to introduce new products and services, create trust, credibility, and competence, while at the same time regulatory compliances require resources, as time and money, which can impede growth. Thus, while regulations can enable some companies to operate in a legal environment, give trust, confidence, and peace of mind to consumers, investors and users, they are associated with some costs and is believed to impede the firm's development.

\section{Proposed Solutions}

Knowing that most of the companies in the sample do agree that it is essential and important to have a legal framework which allows DLT companies to grow their businesses in a regulated environment, they have been asked to provide some suggestions or recommendations to the EU. We have listed the solutions proposed by DLT company owners below.

(1) Education: It is believed that policymakers have to educate themselves or pay consultants for advice and education or corporate with startups or companies that are involved in the technology in order to come up with a legal framework that is applicable to the technology and does not harm further development. One of the company owners states, "EU should assign a young team that understands the technology to work closely with startups and basically just observes what they are doing. Based on those learnings and findings they would then be able to create great regulation." (Interview, Cofounder 6). Another CEO says that "Governments should spread consulting questionnaire to gather a lot of information about the problems that companies are facing and get as many companies or startups to participate. Or, hold round tables and panels with experts to discuss the technology." (Interview, Cofounder 5). It is also believed the consumers and users have to be educated as well. "The best tool is to have the consumer well educated. Since having a welleducated consumer means that they know what they are going through and what will be the consequences of their actions." (Interview, Cofounder 15).

(2) Provide a unified definition and classification of tokens: As mentioned above, lack of a clear and unified 
financial regulation are the main challenges that DLT companies are experiencing. One of the interviewees says: "The EU has to provide an unambiguous and unified definition of what tokens are and how they're going to be treated.” (Interview, Cofounder 5). Another DLT cofounder and CEO says, "Governments should define what tokens are? Are they currencies? Are they commodities? Or are they going to be treated as securities?" (Interview, Cofounder 1).

(3) Provide guidelines: Once the policymakers are educated and some legal frameworks are defined, it is believed that companies should be provided with guidelines on registration, requirements for technology providers, token issuers, and custody service providers. "They (policymakers) should educate themselves and then provide guidelines for the companies that want to set up in Europe." (Interview, Cofounder 8). Another company owner says: "EU can provide guidelines or general benevolence toward Blockchain companies and startups so that they can provide useful services." (Interview, Cofounder 1).

(4) Provide a unified tax regime: It is believed that having a unified and simple tax regime will not only save time but also the money which is spent on accountants and lawyers to identify what has to be paid. A company owner says, "Once the government embraces tokens and defines how taxes can be paid, we will be more than happy to pay for it." (Interview, Cofounder 9).

(5) Be cautious of not over-regulating: This point has been stressed by almost all the company owners. Phrases as "less is more" (Interview, Cofounder 1), and "as little as possible but as much as needed" (Interview, Cofounder 6), "it should not be surpasses" (Interview, Cofounder 10) are used by company owners to emphasize that by regulation they don't mean more restrictions or regulatory compliances, they only want the government to provide clear legal framework. An analogy is provided by one of the company owners. It is said that parents can't prevent children from swimming only because they are afraid that the child can be drawn. The same analogy is applied to DLT regulations, "EU should be alert not to regulate the market too much and injure the progress of the companies and their innovation just to give security and peace of mind to the consumers. [...] I don't like the situation where because of safety people are not trying to learn how to swim." (Interview, Cofounder 6). It is mentioned by another CEO that, "Regulations should not put the company under pressure. I mean, the government should come up with a favorable legal framework to support token companies and protect the consumers from scammers." (Interview, Cofounder 3).

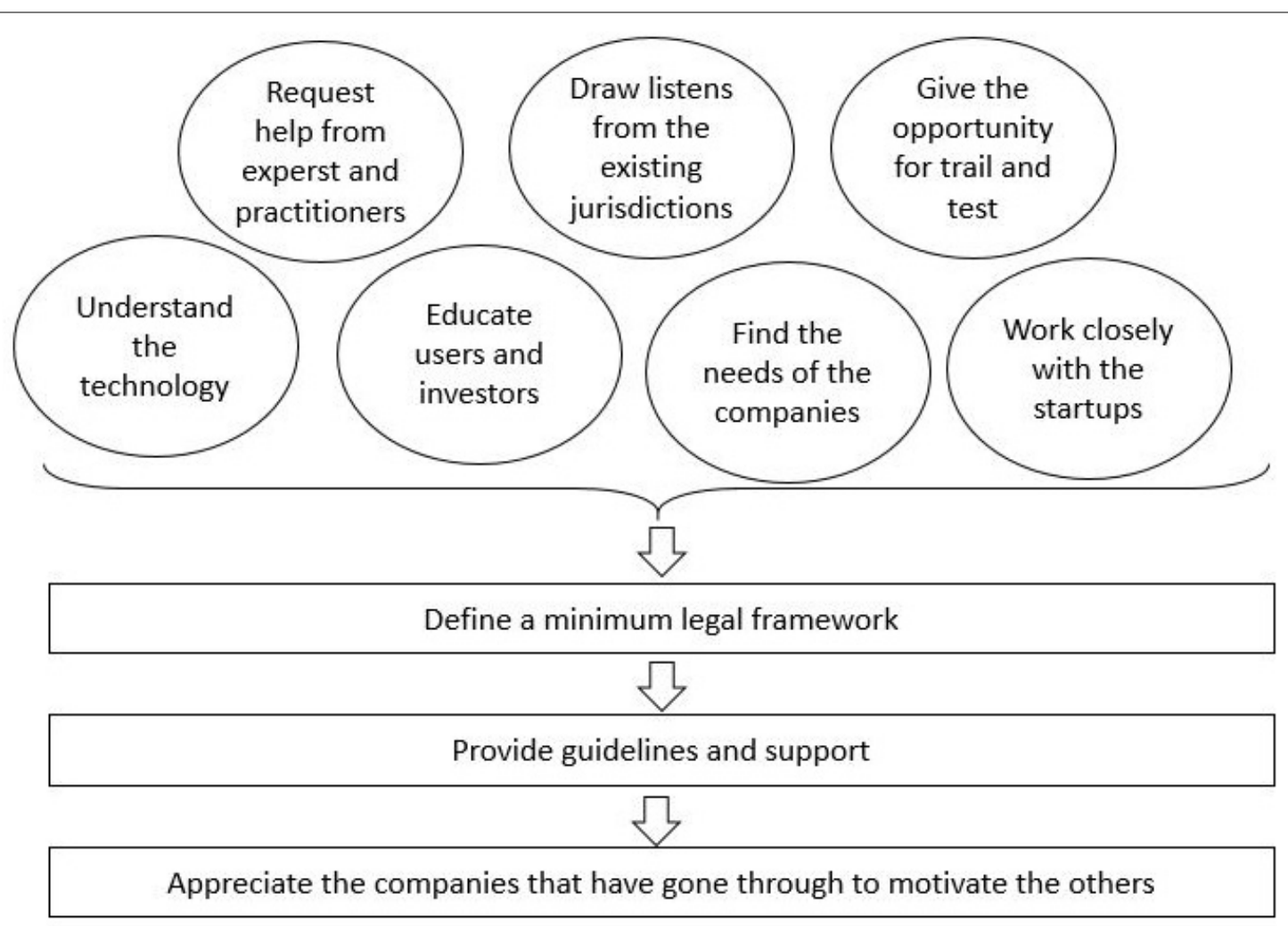

Figure 8. Proposed solutions and EU policy recommendations

FIGURE 4 | Proposed solutions and EU policy recommendations. 
(6) Learning Process: It is believed that companies have to be given the opportunity to test their ideas. It is mentioned that the governments should set a limit after which the companies have to get a license or go through financial regulations as KYC and AML. According to one of the company owners, "One way could be that the government let the companies register and do their activity until they reach a specific volume of sales. As soon as they grow and reach the boundary, ask them to apply for a license." (Interview, Cofounder 6).

In short, it is believed that educating consumers, investors, and policymakers are the key. A clear and unified definition, classification, and tax regime supported with guidelines are required to enable DLT firms to operate in a regulated environment. However, it is pointed out that a balance should be encountered to prevent over regulations. Moreover, companies should be facilitated with precise guidelines. It is also suggested that entrepreneurs should be given an opportunity to trial and experiment.

\section{CONCLUSION AND DISCUSSION}

The paper investigates the impact of financial regulations on the development of DLT companies, mainly; token issuers, trade or exchange platforms, and custody service providers using qualitative semi-structured open-ended interviews. Firstly, some interviews with DLT consulting firms are conducted to acquire some background knowledge, constructing the semi-structured open-ended interviews, and defining the data saturation point. Then, fifteen DLT companies were interviewed to find out company owners and managers perception about the financial regulations, the challenges that the company is experiencing, the impact of those challenges on firms development, and how those challenges could potentially be solved.

The findings of the paper show that almost all company owners and managers in the sample agreed that there should be a minimum regulatory framework out of which the companies operate legally, but the policymakers should be cautious of not surpassing the regulations. The attitude of the interviewees in the sample toward minimum regulations or a clear legal framework is positive. Most of the company owners or managers link passing through regulations to credibility, trust, peace of mind, quality, competence, differentiation, and security. While companies face difficulties in opening a bank account, complying with $\mathrm{AML} / \mathrm{KYC}$, paying taxes, and going through slow and costly existing regulations, they also believe that the EU should come up with a unified definition, classification and tax regime for tokens. Such regulations are assumed to enable growth, increase certainty and stability, and eventually spur innovation.

Thus, the results of the paper support Kitching et al. (2015) regulation dynamic influence theory. It is believed that the impact of financial regulation on DLT firm's development can be ambiguous as it both enables and impedes growth. On the one hand, abiding by the requirements of the existing regulations can be challenging, time-consuming, and costly which can hinder expansion and growth. On the other hand, once the company has gone through it, it can give peace of mind and confidence to the users and is associated with a better, trustworthy, and quality service, which can give credibility and competences to the company. It has also been found out that lack of a clear and certain regulatory environment can harm the companies as they will not be able to execute their plans on time, expand their market, pay taxes, and grow. Thus, financial regulations can be considered as a double-edged sword that, depending on how and by whom and where it is used, can enable or hinder growth.

The amount of regulation is expected to matter as well. Minimum regulations can pave the path for entrepreneurs to operate, while excessive regulations are presumed to stifle innovation and stop entrepreneurs from testing their most innovative ideas. But what would be the limit for financial regulations? One might say "as little as possible, but as much as needed" (Interview, Cofounder 6).

\section{Practical Implementation}

The paper aims to contribute to the existing debut and gap in the literature on the impact of regulations on firms. Specifically, it investigates the impact of financial regulation on the development of DLT firms, a topic that has not been investigated so far in the literature. The findings have practical relevance, as this topic is one of the most concerning issues when it comes to regulating the distributed ledger technologies in the EU. The findings not only give a voice to the small-medium DLT companies but will also fill the information gap that policymakers need for introducing a legal framework that both protects the society and spur innovation.

It has been found out that financial regulations can both facilitate and hinder firms' growth. Thus, legislators should be cautious before defining a legal framework for DLT in order not to over-regulate it and stifle innovation. Some policy recommendations have been given by the company owners and managers to help the lawmakers in defining a practical and supportive legal environment. An illustration can be found in Figure 4.

It can be seen that for a legal framework to work, policymakers should educated themselves and society, better understand the technology, work closely with startups, consult with experts and practitioners, find out the needs of the companies, learn from the jurisdiction that have been enacted in other countries, and give the opportunity for the companies to test the technology with being obliged to go through strict regulations. Once a minimum legal framework is defined, governments should provide guidelines and support to minimize confusion and help the companies to reduce the time and money that they have to spend on legal compliances. Last but not least, the companies that have gone through successfully through the process have to be appreciated to motivate other companies to follow the path. Yet, the findings provide another argument that if regulations are 
designed carefully, they will not only ensure the safety of citizens but will also attract DLT firms, which are considered to be the backbone of any economy.

\section{ETHICS STATEMENT}

Ethical review and approval was not required for the study on human participants in accordance with the local legislation and institutional requirements. Written informed consent from the participants was not required to participate in this study in accordance with the national legislation and the institutional requirements.

\section{REFERENCES}

Achtenhagen, L., Ekberg, S., and Melander, A. (2017). Fostering growth through business development: core activities and challenges for microfirm entrepreneurs. J. Manag. Organ. 23, 167-185. doi: 10.1017/jmo. 2016.58

Capelleras, J. L., Mole, K. F., Greene, F. J., and Storey, D. J. (2008). Do more heavily regulated economies have poorer performing new ventures? Evidence from Britain and Spain. J. Int. Bus. Stud. 39, 688-704. doi: 10.1057/palgrave. jibs. 8400340

Carson, B., Romanelli, G., Walsh, P., and Zhumaev, A. (2018). Blockchain Beyond the Hype: What Is the Strategic Business Value? London: McKinsey \& Company.

Chohan, U. (2018). Oversight and regulation of cryptocurrencies: BitLicense. SSRN Electron. J. 4. doi: 10.2139/ssrn. 3133342

Creswell, J. (2006). "Five qualitative approaches to inquiry," in Qualitative Inquiry and Research Design. 2nd Edn. (New York, NY: Sage Publication).

European Central Bank (2016). Distributed Ledger Technology. Frankfurt: European Central Bank.

Guest, G., Bunce, A., and Johnson, L. (2006). How many interviews are enough: An experiment with data saturation and variability. Field Methods 18, 59-82. doi: 10.1177/1525822X05279903

Jalilian, H., Kirkpatrick, C., and Parker, D. (2007). The impact of regulation on economic growth in developing countries: a crosscountry analysis. World Dev. 35, 87-103. doi: 10.1016/j.worlddev.2006. 09.005

Kitching, J., Hart, M., and Nick, W. (2015). Burden or Benefit? Regulation as a dynamic influence on small business performance. Int. Small Bus. J. 33, 130-147. doi: 10.1177/0266242613493454

Lacity, M. C. (2018). Addressing key challenges to making enterprise blockchain applications a reality. MIS Q. Execut. 17:3.

\section{AUTHOR CONTRIBUTIONS}

LH and PS conceived and outlined the presented manuscript. LH did the implementation of the research, to the analysis of the results, and to the writing of the manuscript. PS provided critical feedback and revised the manuscript. PS supervised the project. All authors contributed to the final version of the manuscript.

\section{ACKNOWLEDGMENTS}

The authors would like to thank Emili Grifell-Tatjé for providing critical feedback.

Mayson, S., Barrett, R., and Bahn, S. (2014). Stream 6 HRM Competitive Paper Competitive Advantage through Safety Compliance: Smaller Firm Responses to Changes in the Australian Occupational Health and Safety Regulatory Context. Brisbane: QUT Business School.

Peck, F., Jackson, K., and Mulvey, G. (2018). Regulation and growth-oriented small businesses in North-West England. J. Small Bus. Enterprise Dev. 25, 294-312. doi: 10.1108/JSBED-07-2017-0232

Poel, K., Marneffe, W., Bielen, S., Van Aarle, B., and Vereeck, L. (2014). Administrative simplification and economic growth: a cross country empirical study. J. Bus. Admin. Res. 3:45. doi: 10.5430/jbar.v3n1p45

Tapscott, D., and Tapscott, A. (2016). Blockchain Revolution: How the Technology Behind Bitcoin Is Changing Money. New York, NY: Sage Publications, Inc.

Tsukerman, M. (2016). The Block Is Hot: A Survey of the State of Bitcoin Regulation and Suggestions for the Future. Berkeley Technol. Law J. 30:44.

World Bank (2014). Doing Business 2014: Understanding Regulations for Small and Medium-Size Enterprises. Washington, DC: World Bank Publications.

Yeoh, P. (2017). Regulatory issues in blockchain technology. J. Finan. Regul. Compl. 25, 196-208. doi: 10.1108/JFRC-08-2016-0068

Conflict of Interest: The authors declare that the research was conducted in the absence of any commercial or financial relationships that could be construed as a potential conflict of interest.

Copyright (c) 2020 Hashimy and Sandner. This is an open-access article distributed under the terms of the Creative Commons Attribution License (CC BY). The use, distribution or reproduction in other forums is permitted, provided the original author(s) and the copyright owner(s) are credited and that the original publication in this journal is cited, in accordance with accepted academic practice. No use, distribution or reproduction is permitted which does not comply with these terms. 